\title{
Darwin's enduring legacy
}

\section{As the 200th year since the great naturalist's birth begins, Kevin Padian looks forward to a season of celebration by outlining how Darwin's ideas changed scientific thinking.}

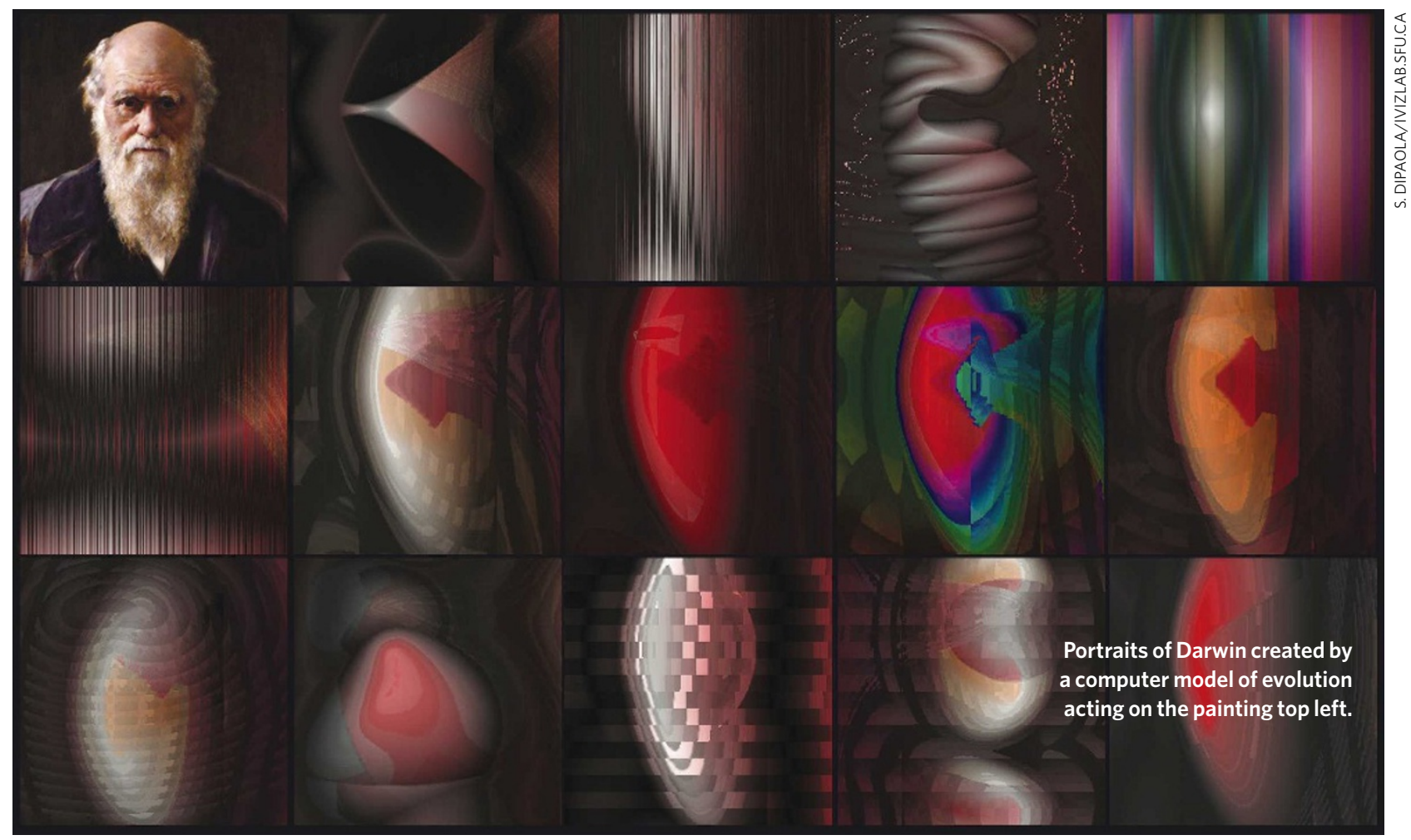

\section{Kevin Padian}

Perhaps no individual has had such a sweeping influence on so many facets of social and intellectual life as Charles Darwin, born on 12 February 1809. Of the other two of the great nineteenth-century triumvirate of European thinkers, Marx's ideas have been distorted beyond recognition in their political execution, and Freud's approach to the psyche no longer merits scientific recognition. Neither man had Darwin's impact on the structure of empirical knowledge.

In the past century and a half, Darwin's ideas have inspired powerful images and insights in science, humanities and the arts. Meanwhile, countless commentators ignorant of his meaning have borrowed his eloquence to plump their own chickens - from capitalism to 'evolutionary psychology'. Darwin has been invoked as the demon responsible for a variety of perceived heartless ills of society, including atheism, Nazism, communism, abortion, homosexuality, stem-cell research, samesex marriage, and the abridgement of all our natural freedoms. One can scarcely imagine the horror that Darwin would feel at the misunderstanding, misappropriation and vilification of his ideas in the 125 years since his death.
As we prepare to mark next year the 200th anniversary of Darwin's birth and the 150th of the publication of On the Origin of Species, it is an opportune time to reflect on just what constitutes Darwin's enduring greatness in Western thought. His contributions can scarcely be reduced to a simple list, but the following ten topics hint at the magnitude of the man's legacy.

\section{Grandeur in this view}

Natural selection Both Darwin and his co-discoverer of natural selection, Alfred Russel Wallace, were partly inspired by the social economic theory of Thomas Malthus. Malthus noted in his great Essay on the Principle of Population (1803) that population growth would always outstrip resource growth, so overpopulation and insufficient supply are inevitable and should be accepted and dealt with. Darwin and Wallace independently applied these principles to the natural world. More offspring are produced than can survive; some are better suited to the prevailing conditions than others; and those better-suited individuals are more likely to leave their advantageous heritable features to the next generation. Malthus may have been the godfather of the workhouses, designed to deter citizens from insolvency and dependence on the public weal, but his bleak view of amelioration was not Darwin's, any more than was Herbert Spencer's appropriation of natural selection for his social manifesto of the "survival of the fittest".

Darwin was less emphatic than Wallace about the pre-eminence of natural selection among other mechanisms of evolutionary change. But he did think it was important, and it provided a plausible process for the transmutation of species that made the concept of common descent of all species respectable, given what was understood of heredity in Darwin's day.

On the other hand, mathematicians ignorant (like Darwin) of the genetic underpinnings of heredity soon produced demonstrations that natural selection could have little real effect on species, and the whole idea fell into some disfavour, even in Darwin's lifetime. It was rescued, ironically, by the mathematical modellers of the Modern Synthesis of evolutionary theory in the 1930s. Ronald Fisher, Sewall Wright and J. B. S. Haldane showed, among other things, that even small selective advantages could permanently affect evolution in populations. They brought back natural selection with a quantifiable vengeance, and it has been 
the primary focus of evolutionary research ever since.

One tree of life A sketch Darwin made soon after returning from his voyage on HMS Beagle (1831-36) showed his thinking about the diversification of species from a single stock (see Figure, overleaf). This branching, extended by the concept of common descent, eventually formed an entire 'tree of life', developed enthusiastically by his German disciple Ernst Haeckel in the decades following the Origin. The unity of life gained independent confirmation, of course, with the discovery of genetic structure more than a century after the Origin was published.

Genealogical classification Before the acceptance of common ancestry, classifications were attempts to discern some shadowy philosophical or theological 'natural system' to organize biological similarity. The tree of life implied that relatedness was what Darwin called the "hidden bond underlying all our classifications". He insisted in letters and books throughout his career that classifications should be, as far as possible, genealogical. Yet in his own work on barnacles he found it difficult to construct classifications based solely on common ancestry, because the animals had been so highly modified. This led to another essential, often overlooked, keystone of his work:

\section{Selective extinction}

Extinction had been recognized as a fact since the mid-eighteenth century. It took Darwin to recognize the extent to which

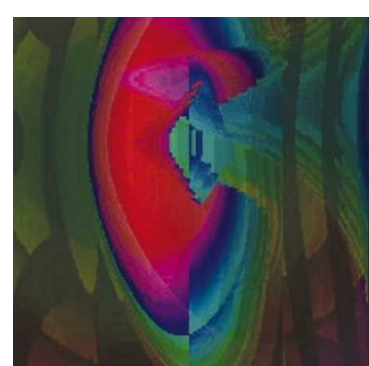

it has shaped the contours and lacunae of diversity through time. Far from preserving a "great chain of being", the living world is a patchwork of possible forms, with most transitional stages and features removed. This explains at once why it is so easy to separate living things into discrete major groups (phyla and so on) and why it is so difficult sometimes to link them, as Darwin found with his barnacles.

Deep Time This apt phrase was not known in Darwin's time, but was an inevitable concept. Darwin wrote in the Origin that any reader who has not grasped the incredible stretch of time required for biological evolution "may at once close this book". He was serious. He calculated the period necessary to build up and wear down many of the major rock formations of England, to underscore the point. True, Lord Kelvin's calculated limits on solar duration nonplussed many supporters of Deep Time, but Darwin was not cowed by physics, because he knew the rocks. Deep Time was absolutely necessary to his theory, in a way that it had not been for any biological theory before. It was no longer possible to accept that Earth was 6,000 years old, as some Biblical scholars estimated.

Biogeographical distributions If species can diversify, if they change by adapting to new circumstances and opportunities, if they can migrate, and if climates have changed through time, then the distributions of plants and animals are not serendipitous patterns or whims of a Creator. Darwin saw that upland and lowland rodents in North and South America were most closely related to their continental neighbours, not to their ecological counterparts on separate continents. Only evolutionary adaptation and dispersal could account for such patterns.

In Darwin's day, dispersal through migration was the only mechanism thought possible for species to move among continents. A century after the Origin, plate tectonics provided the second major mechanism for moving species and changing biogeographic distributions.

Sexual selection Darwin realized that other forces besides natural selection might influence the evolution of form in species. He noticed that the differences between sexes in many species, from beetles to marine invertebrates to birds and mammals, could be important in mate choice, and that this would affect the reproductive success of the next generation. His exposition of sexual selection was the subtitle of the otherwise curiously named The Descent of Man. Differences between sexes could now be explained as the result of processes of mate choice and territorial competition, not merely as of divine design.

Coevolution One of Darwin's lesser-known books is On the Various Contrivances by which British and Foreign Orchids are Fertilised by Insects and on the Good Effects of Intercrossing (1862). It encapsulates the concept that species of very different origins have evolved mutual ecological relations through time that have come to affect critical aspects of their morphologies. An African orchid was discovered that had a corolla nearly a foot long. Darwin inferred that there must be a moth with a tongue long enough to extract its pollen. When the moth sub-species was eventually discovered, it was given the name praedicta. Today we can identify groups of plants and their insect predators, vertebrates and their parasites, lichens composed of an alga and a fungus, and many other associations that can only reasonably be explained by coevolution through diversification over millions of years.

Economy of nature Darwin invented many ideas that currently constitute the science of ecology, although the word 'ecology' was unknown in his day. He developed the idea of "the economy of nature" - the inter-relations of species in a community, like businesses and consumers in a society. What had been, for earlier authors, the divinely ordained balance of nature became the autocatalytic war of nature. He acknowledged the "tangled bank" of species in a community, and outlined the dynamic between biological and physical influences on the distribution and survival of species. Darwin became increasingly persuaded of the importance of biological processes, and his emphasis on the influences of competition and predation on survival continues to dominate ecology.

Gradual change It is widely, and correctly, recognized that Darwin promoted gradual change. But what did he mean by 'gradual'? Most dictionary definitions have it as 'slow and steady', and this is indeed one meaning that Darwin used. There is another. On the Beagle voyage, Darwin landed at Concepción, Chile, just after a great earthquake had demolished hundreds of buildings, killed and injured many, caused a huge tsunami and thrown the cliffs several metres higher up along the coastline, leaving putrefying sea creatures still attached to the formerly submerged rocks. Darwin, inspecting the coastline the next day, and seeing evidence of many such changes in hundreds of feet along the terraced cliffs, described this in his journal as a "gradual" change. To understand why, we must consider the etymology of the word 'gradual', which comes from the Latin gradus, meaning 'step'. The geological change was steplike: gradual. This conceptual tension between 'slow and steady' and 'step-like' is the basis of one of the most important evolutionary ideas of the twentieth century: punctuated equilibria. This generalization is based on myriad fossil examples showing that the morphology of species may not change appreciably for much or most of their history, then alter relatively rapidly. If this turns out to be the predominant pattern of evolution in well-preserved fossil sequences, as now seems to be the case, Darwin's view of the plurality of evolutionary tempos and modes will be vindicated.

\section{From so simple a beginning}

The list above, which is by no means complete, prompts the question: has any single individual made so many lasting contributions to a broad area of science as Darwin 


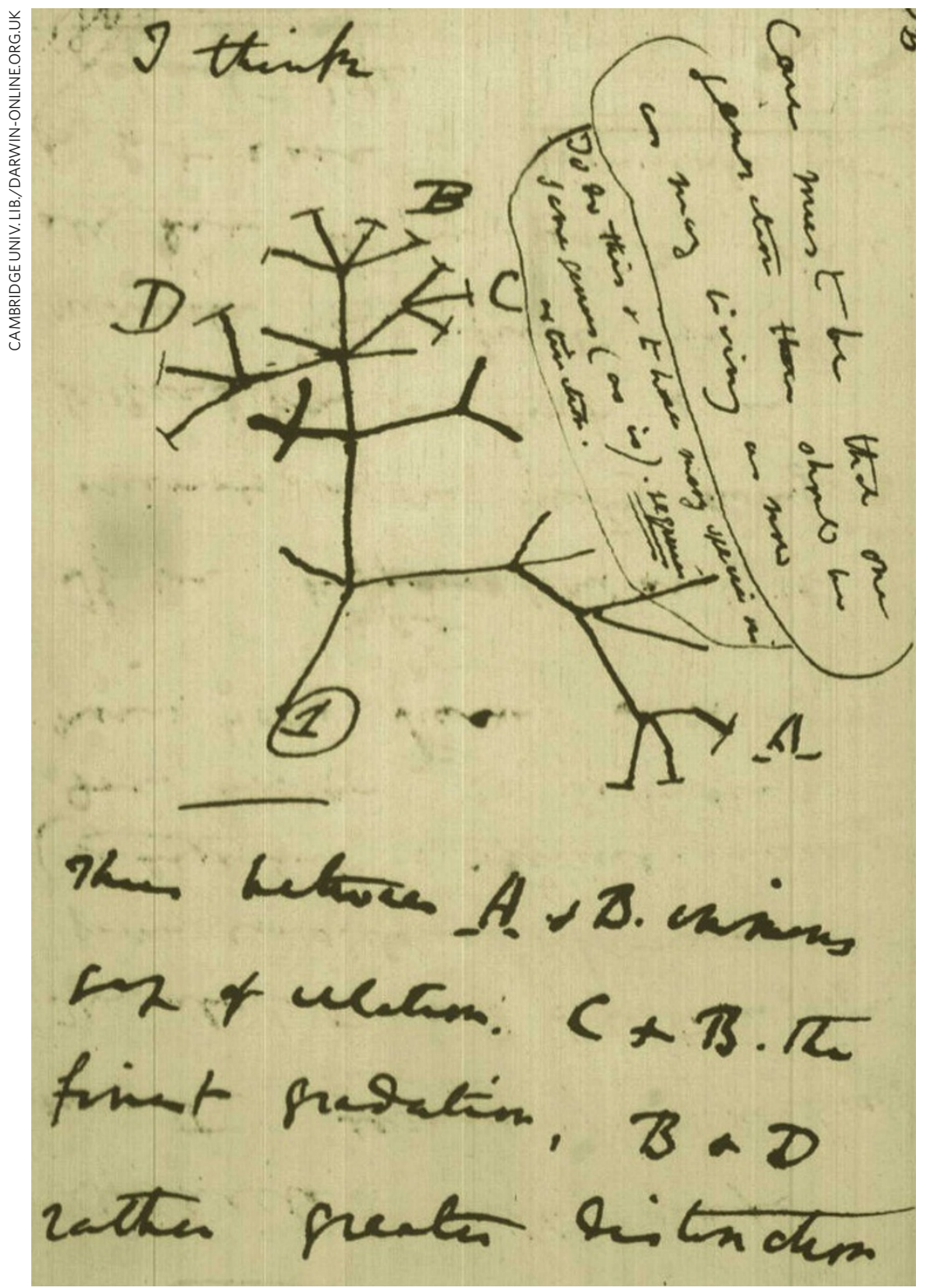

Charles Darwin's 1837 sketch of the diversification of species from a single stock.

did to biology? Certainly the history of Western thought is graced by many polymaths and geniuses and comparisons are ultimately meaningless.

But Darwin moved intellectual thought from a paradigm of untestable wonder at special creation to an ability to examine the workings of that natural world, however ultimately formed, in terms of natural mechanisms and historical patterns. He rooted the classification of species within a single branching tree, and so gave systematics a biological, rather than purely philosophical, rationale. He framed most of the important questions that still define our understanding of evolution, from natural selection to sexual selection, and founded the main principles of the sciences of biogeography and ecology. His work is still actively read and discussed today, inspiring new students and scientists all over the world. Few authors can claim so much.
It is dismaying, then, to note the rise of anti-evolutionism in recent decades. This is a direct result of the rise of religious fundamentalism, whose proponents feel it necessary to reject modern science on the basis of highly questionable (from mainstream historical and theological viewpoints) readings of sacred texts.

\section{Divergence of character}

One might well ask how such people can accept the benefits of medical research, inoculations, pharmacology, crop improvement and so much more that depends on an understanding of evolution. Most of them reject the evolutionary basis of these advances, regarding it simply as 'variation' that can be selected like features of dog breeds. This is why 'microevolution' in populations poses little threat to fundamentalists, and perhaps why even most evolutionary scientists (dominated by population biologists) have not been intensely engaged in the defence of evolution against its detractors. There is no evidence that Darwin thought in modern populational terms, but he did feel that the changes in species wrought by natural selection and other processes would eventually lead to new kinds of organisms with new adaptations - a premise violently rejected by fundamentalists and other anti-evolutionists.

Happily, in one non-scientific arena at least, an honest, almost organic understanding and appreciation of Darwin has flourished. This is in literature, where authors from George Eliot to John Fowles have consciously or unconsciously absorbed his precepts and insights, nourishing beautiful prose and poetry. None, perhaps, more so than Thomas Hardy, who intuitively understood Darwin's layers of deep time, historical contingency, hereditary predilections and weaknesses, environmental opportunities, the various scales of change that comprise evolution, the constant need to adjust - and especially the insignificance of individuals against the great flow of life and time.

As Hardy put it: "Let me enjoy the earth no less / Because the all-enacting Might / That fashioned forth its loveliness / Had other aims than my delight." This child of the Enlightenment was well aware of more ancient world views, and humbled by what the new investigations of the cosmos revealed. Humans are animals, one species of many on the planet, bound by common ancestry to all other species, part of an ages-old dance of reproduction, accommodation, survival and alteration.

It is for this vision, one that liberates humans from the conceit of special creation, that Darwin was honoured by interment in Westminster Abbey. And it is for his innumerable scientific insights, most still as valid and stimulating as the day he coined them, that we look forward to celebrating him next year.

Kevin Padian is professor of integrative biology and curator in the Museum of Paleontology, University of California, Berkeley, and president of the National Center for Science Education, Oakland, California. He served as an expert witness in the Dover, Pennsylvania, 'intelligent design' trial in 2005.

\section{FURTHER READING}

Desmond, A. J. \& Moore, J. Charles Darwin: The Life of a Tormented Evolutionist (Warner, New York, 1991). Browne, J. Charles Darwin: Voyaging (Princeton Univ. Press, 1996).

Quammen, D. The Reluctant Mr. Darwin (Norton, New York, 2006)

Ellegård, A. Darwin and the General Reader (Univ. Chicago Press, 1958).

Eldredge, N. \& Gould, S. J. in Models in Paleobiology (ed. T. J. M. Schopf) 82-115 (Freeman, Cooper \& Co., San Francisco, 1972).

Padian, K. Nature 390, 460 (1997). 